\title{
The relationship between the air void system and frost-salt resistance of concrete
}

\author{
* HuarongSHEN ${ }^{1, a}$,Yang JIANG ${ }^{1, b}$ and Jiangtao $X^{1} A^{1, c}$ \\ ${ }^{1}$ Faculty of Architecture and Civil Engineering, Huaiyin Institute of Technology, Huaian, China \\ a shr650816@163.com, bjiangyang@hyit.edu.cn, xjthyit@163.com
}

\begin{abstract}
Keywords:concrete; the air void spacing factor; frost-salt scaling;air content
\end{abstract}
Abstract.The frost-salt resistances of concrete were investigated according to the CDF methodeffects of air void systems introduced by different air entraining agent. The results showed that the frost-salt resistance of concrete increased with the decreasing of spacing factor and increasing of air content. The speed of frost-salt scaling of concrete was reduced when the spacing factor less than $0.200 \mathrm{~mm}$. The results also showed that the frost-salt resistance of concrete of different surface exist difference. The frost-salt resistance of concrete can improve by controlling of the spacing factor not the air content.

\section{Introduction}

In architecture field, such as high-rise buildings, airfield runway and roads, cement concrete has been the ideal material because of its high intensity and stiffness, good stability and durability, simple maintenance and low cost of construction. In the future, cementconcrete will continue to be an indispensableconstructionmaterial and is developed ahead towards high performance, high strength and multifunction. At the same time, the drawbacks of high-intensity cement concrete, great deformation and brittleness also have side-effects to its wide application. And how to make control of the shrinkage distortion and cracks has become a hot issue in engineering ${ }^{[1]}$.

There is one way to overcome this drawback, and the most effective and easiest way is mixing fiber into road concrete. "The main way to improve the performance of cement-based materials is combination and the fibrous reinforcement is the core. "said Wu Zhongwei, a member of the Chinese Academy of Engineering and famous concrete expert ${ }^{[2-4]}$. Fibres mainly include: glass fiber, polypropylene fiber, steel fibre and carbon fiber. The polyvinyl alcohol fiber(PVA) which is high-intensitive and high-elastic has superior performances: 1)high-intensity and high elasticity modulus, the elasticity modulus is just inferior to steel fibre, glass fiber, carbon fiber and ultra-high molecular weight polyethylene fiber(UHMWPEF) and the strength of extension is as good as steel fibre, glass fiber, carbon fiber, UHMWPEF and PPTA; 2) good mechanical properties which can Improve the toughness and impact strength of concrete.; 3)good chemical compatibility with concrete; 4) good hydrophilicity which makes it homodisperse in the concrete; 5) good interface bonding strength between PVA fiber and cement matrix; 6) favorablelight resistance and acid-base resistance property which is suitable to each level of cement concrete; 7) good chemical stability ${ }^{[5]}$.

The application of PVA in concrete materials in China is just under development ${ }^{[6-7]}$. Adding PVA fibers in concrete can improve the anti-cracking ability and tenacity of concrete and has important engineering value and widely application foreground because of the high-intensity, high elasticity modulus, good hydrophilicity, acid-base resistance property and security of PVA fiber. Nowadays, though researches on the effects of the types and specifications of PVA fiber on concrete performance are being carried out, there is few researches and reports on the effects of PVA fiber on concrete condensation. In fact, it is very important and indispensable to study this to make control of shrinkage crack of high-performanceconcrete ${ }^{[8-11]}$. 


\section{Experiment method and materials}

\section{Experiment materials}

The materials include Huaxin 42.5 MPa(ISO) ordinary cement hydrochloride produced by Nantong cement co., LTD; I-level fly ash produced in Zhenjiang; river sands with a 2.6 fineness modulus from the Ganjiang River (in Jiangxi Province); lumps of basalt with grain size ranged from 5 to 20 millimeters from MaoDi. The water reducer used in this research is composite additive :JM-PCA (I) superplasticizerWith carboxylic acid as the main body produced by Jiangsu both new materials co., LTD.Thepolyvinyl alcohol fiber is Q1 and the polypropylene fiber is I rack resistance fibre. The performance indicators of fiber are shown in Table 1.

Table 1 The physical and mechanical properties of fibers

\begin{tabular}{ccccccc}
\hline Type & $\begin{array}{c}\text { Diameter } \\
/ \mu \mathrm{m}\end{array}$ & $\begin{array}{c}\text { Length } \\
/ \mathrm{mm}\end{array}$ & $\begin{array}{c}\text { Tensile } \\
\text { strength } \\
/ \mathrm{MPa}\end{array}$ & $\begin{array}{c}\text { Young } \\
\text { modulus } \\
/ \mathrm{GPa}\end{array}$ & $\begin{array}{c}\text { Elongation at } \\
\text { break } \\
/ \%\end{array}$ & $\begin{array}{c}\text { Density } \\
/(\mathrm{g} / \mathrm{cm} 3)\end{array}$ \\
\hline $\begin{array}{c}\text { polyvinyl } \\
\text { alcohol fiber } \\
\text { polypropylene } \\
\text { fiber }\end{array}$ & 20 & 9 & 1300 & 37 & 7 & 1.29 \\
\hline
\end{tabular}

\section{Experiment equipment}

The condensation specimen used is hollow cylindrical steel tube with a 3-mm polytetrafluoroethylene pipes inside and a detachable base, the inner diameter is 98 millimeter and free height is 500 millimeter. The mould is put on a marble countertop[12]. The eddy-current transducer used is non-contact type produced by MICRO-EPSILON (Multi NCDT 300), range of measurement:1millimeter,linearity: $0.2 \%$, resolution ratio: $0.01 \%$, sensor temperature range: $-50 \sim 150^{\circ} \mathrm{C}$, temperature stability: $0.02 \% /{ }^{\circ} \mathrm{C}$. The mould and testing equipment is shown in Fig. 1.

\section{Experiment method and mixture ratio}

The double PVC plastic film is put in the mould before moulding,

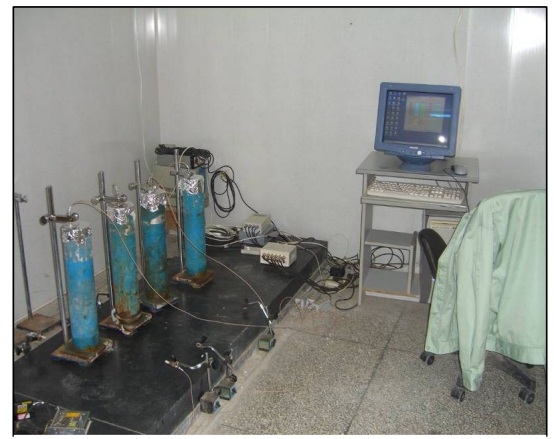

Fig.1 Measure system for settlement shrinkage of concrete sealing grease is smeared between the base and steel tube. Die-filling right after the concrete has been stirrered, seal the top of the steel tube to prevent evaporation, and we start to Test the initial value half an hour after we mixed with water. Mix proportions of concrete is shown in Table 2.

Table 2 Mix proportions of concrete for settlement shrinkage test $\left(\mathrm{kg} / \mathrm{m}^{3}\right)$

\begin{tabular}{lccccccc}
\hline Type & Cemen & water & $\begin{array}{l}\text { san } \\
\mathrm{d}\end{array}$ & cobblestone & flyash & $\begin{array}{l}\text { water } \\
\text { reducer }\end{array}$ & fiber \\
Plain & 388 & 165 & 668 & 1136 & 129 & 6.2 & $/$ \\
PVA0.9 & 388 & 165 & 668 & 1136 & 129 & 6.2 & 0.9 \\
PVA12.8 & 388 & 165 & 668 & 1136 & 129 & 6.2 & 12.8 \\
PP0.9 & 388 & 165 & 668 & 1136 & 129 & 6.2 & 0.9 \\
\hline
\end{tabular}

There is a sheetmetal set for eddycurrent type transducer and a plastic strip to float the sheetmetal on the concrete, the real height of the concrete sample is 498 millimeter. Condensation value can be calculate with the equation listed below:

$$
\varepsilon_{V t}=1000000 \times \frac{l_{0}-l_{t}}{498}
$$


In this equation: $\varepsilon_{v t}-$ condensation value at stadiumt $\left(\times 10^{-6}\right) ; l_{0}$-Initial time reading number $(\mathrm{mm}) ; l_{t}-$ reading number at stadium $\mathrm{t}(\mathrm{mm})$ 。

\section{Results and discussion}

\section{Effects of fibers on condensation of early high- strength concrete}

Influence of PVA fiber content on settlement shrinkage of concrete is shown in Fig. 2.

Early condensation value of high-strength concrete before initial setsignificantly reduced when it is added with PVA fiber. When the time was at 360 minutes, the condensation value of PVA0.9 reduced about $12.6 \%$ that of plain concrete; when the fiber contentchanged from $0.9 \mathrm{~kg} / \mathrm{m} 3$ to $12.8 \mathrm{~kg} / \mathrm{m} 3$, the condensation value reduced about $19.4 \%$ that of plain concrete. It is easily to conclude that when the fiber content is larger than $0.9 \mathrm{~kg} / \mathrm{m} 3$, the improvement of PVA fibers on condensation do not increase significantly as the decrement of condensation only increased about $7 \%$ when the PVA content increased by 13.2 times.

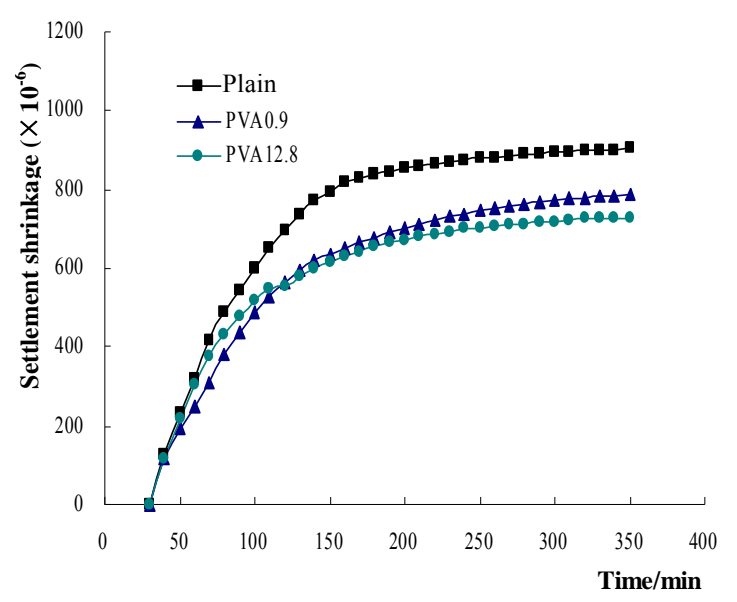

Fig. 2 Influence of PVA fiber content on settlement shrinkage of concrete

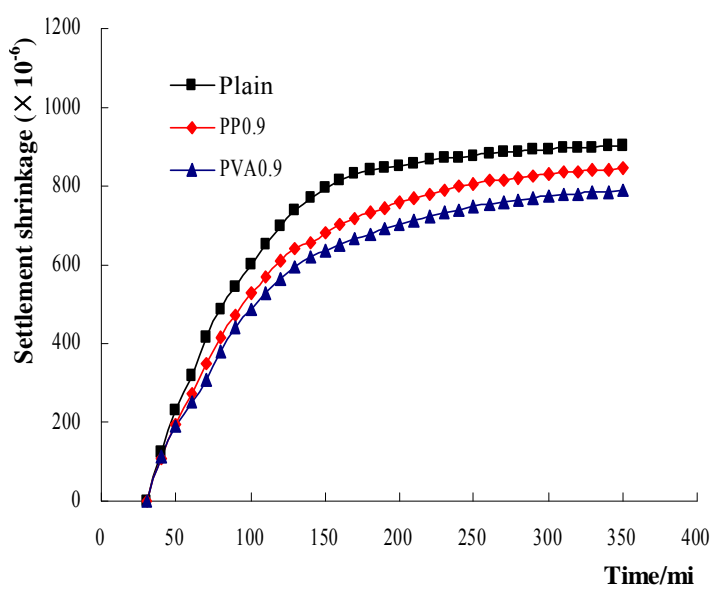

Fig. 3Influence of different fibers on the settlement shrinkage of concrete

Influence of different fibers on the settlement shrinkage of concrete is shown in Fig. 3.

It is shown in Fig. 3 that the condensation of concrete added with PP fiber reduced $6.5 \%$ at 360 minutes while those added with PVA fiber reduced $12.6 \%$ at the same time and it is easy to conclude that PVA fiber is much better in reducing concrete condensation and is twice as good as PP fiber. In fact, this phenomenonhas a close relation with hydrophilicity of PVA fiber. Because of the hydrophilic group $(-\mathrm{OH})$ in PVA fibers which can bond well with cement matrix, the traction between PVA fiber and concrete matrix stops the sinking of aggregates and the rising of slurryeffectively, besides, the thickening effect of PVA fiber on cement matrix prohibits the sinking of aggregate in concrete.

\section{The observation of cement paste added with fibers}

The morphology of cement paste added with PVA fiber and PP fiber are shown in Figure 4 and 5.

Fig. 4 shows that the hydration products accumulating on the surface and root segment of PVA fiber clearly. The large amount of hydration products on the surface of PVA fibers on fractured face shows well adhesion between hydration products and fiber and also provides strong support to prove the cohesive force between fiber and cement matrix in hardened cement matrix so that they can form aunifiedwhole which is better for improving the mechanical property of concrete.

Fig. 5 shows few hydration products on PP fiber which means the adhesive property between PP fiber and cement matrix is very weak. At the same time, the interval between cement paste and the root segment of fiber is also found which means the debonding phenomena exists and it is not good for the mechanical property and durability of concrete. 


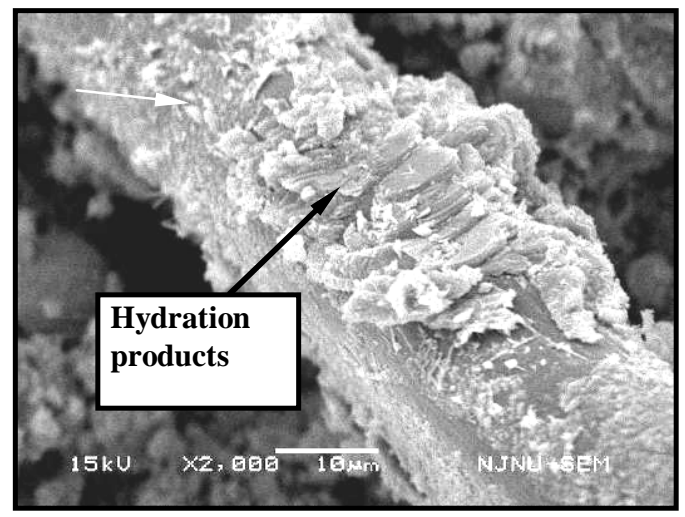

Fig. 4 Hydration products on surface of PVA fibers

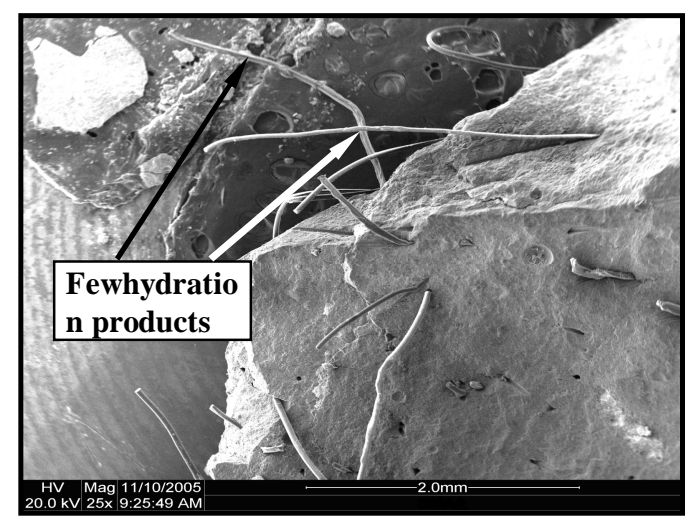

Fig. 5Few hydration products on surface of

\section{The mechanism of how PVA fiber prohibits the condensation of concrete}

As shown in Fig. 6, the addition of PVA fiber increase the consistency of the concrete so as to inhibits the sinking of aggregates in the cementitious materials. The PVA fiber forms a filamentous network in the plastic concrete and as a result, this filamentous network inhibits the sinking of aggregate and this is difference between the PVA fiber and steel fiber and polypropylene fiber. The steel fiber provides disoriented support in concrete matrix to inhibit the sinking of aggregates to reduce bleeding as it is rigid while polypropylene fiber increases the consistency and viscidity of concrete to inhibit the sinking of aggregates as it is flexible. The PVA fiber is a kind of synthetic fibre which is also flexible. The addition of PVA fiber into concrete not only improves the consistency and viscidity of the matrix to

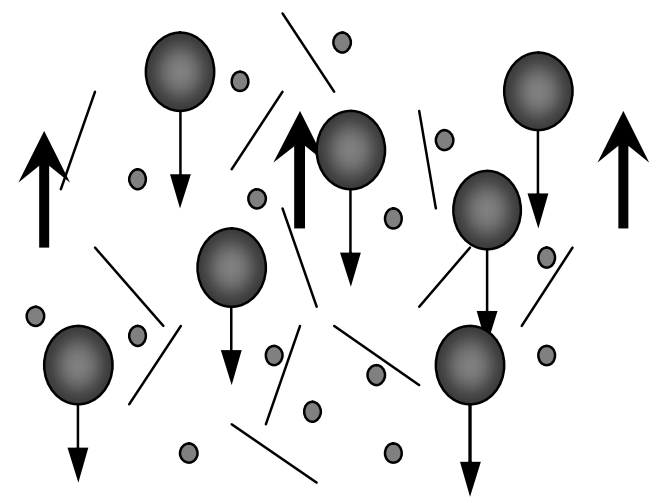

Fig.6 Model of concrete settlement shrinkage with PVA fiber inhibit the sinking of aggregates but also inhibits the mobility of slurry and the movement of the aggregates in the concrete because of its good hydrophilicity and bond force with binding materials: when the sinking of aggregates results in the movement of slurry, the PVA fiber and the slurry will check and balance each other.

\section{Conclusion}

Adding PVA fiber can significantly reduce the condensation value of concrete, but when the fiber added increased to $0.9 \mathrm{~kg} / \mathrm{m} 3$ there is no significant reduction of condensation despite of more added PVA fibers.

PVA fiber's improvement of condensation value has close relation with its hydrophilicity: the hydrophilic group (-OH) in PVA fiber has good adhesion performance with cement matrix.

After dispersing in the concrete, the PVA fiber forms a filamentous network and as a result, it increases the consistency of the concrete, inhibits the sinking of aggregates and the come-up of the slurry in the cementitious materials so as to reduce the condensation of concrete.

\section{References}

[1]Deng Zongcai. High-performance synthetic fiber reinforced concrete [M]. Beijing: Science Press, 2003.

[2]WuZhongwei. Fiber reinforced-Future of cement-based materials[J]. China Concrete and Cement Products, 1999, 1: 5-6. 
[3] GaoPeiwei. Effects of fly ash on the properties of environmentally friendly dam concrete [J]. Fuel, 2007, 86(7-8): 1208-1211.

[4] Wang Haibo. The researchment of Polyfiber reinforced mortar performance[D]. Master thesis. Beijing: Beijing University of Technology, 2003.

[5] Padron I. and Zollo F. Effect of synthetic fibers on volume stability and cracking of Portland cement concrete and mortar. ACI Material Journal, 1990, 85(4): 327-332.

[6]Wang Xiaogang, Mao Xinqi, Zhao Tiejun. Polyvinyl alcohol Fiber-Engineered Cementious Composites[J]. Journal of Qingdao Institute of Architecture and Engineering, 2004, 25(4): 28-31.

[7] Kim J. H., Robertson R. E. and Naaman A. E. Structure and properties of poly(vinyl alcohol)-modifiedmortar and concrete[J]. Cement and Concrete Research, 1999, (29): 407-415.

[8] Salah A. A1toubat and David A. Lange. Creep, Shrinkage and Cracking of Restrained Concrete at Early Age [J]. ACI Materials Journal, 2001,98(4): 323-331.

[9] GaoPeiwei, Tang Mingshu. The influence of expansive agent on deformation performance of concrete[J]. Journal of Nanjing University of Aeronautics and Astronautics, 2006, 38(2): 251.

[10] R. N. Swamy etc. Deformation and ultimate strength in flexure of reinforced concrete beams made with steel fiber concrete [J]. ACI Journal, Proceedings, 1981, 5: 78.

[11] GaoPeiwei. The strength and toughmess of fiber reinforced concrete[J]. Materials Science and Engineering, 1990, (1): 18-21.

[12] TianQian, Sun Wei, Liao Changwen. Study on the Measurement of Autogenous Shrinkage of High Performance Concrete[J]. Journal of Building Materials, 2005, 8(1): 82-89. 